\title{
Mass attenuation coefficient calculations of different detector crystals by means of FLUKA Monte Carlo method
}

\author{
Elif Ebru Ermisa ${ }^{a}$ Cuneyt Celiktas \\ Ege University, Faculty of Science, Physics Department, 35100, Bornova, Izmir/Turkey
}

\begin{abstract}
Calculations of gamma-ray mass attenuation coefficients of various detector materials (crystals) were carried out by means of FLUKA Monte Carlo (MC) method at different gamma-ray energies. NaI, PVT, GSO, GaAs and $\mathrm{CdWO}_{4}$ detector materials were chosen in the calculations. Calculated coefficients were also compared with the National Institute of Standards and Technology (NIST) values. Obtained results through this method were highly in accordance with those of the NIST values. It was concluded from the study that FLUKA MC method can be an alternative way to calculate the gamma-ray mass attenuation coefficients of the detector materials.
\end{abstract}

\section{Introduction}

If gamma-rays are allowed to pass through an absorber, the result should be simple exponential attenuation of the gamma-rays. Each of the interaction processes removes the gamma-ray from the beam either by absorption or by scattering. It can be characterized by a fixed probability of an occurrence per unit path length in the absorber and is called linear attenuation coefficient [1], i.e.;

$$
\mathrm{I}(\mathrm{x})=\mathrm{I}_{0} \mathrm{e}^{-\mu \mathrm{t}}
$$

with $\mathrm{I}_{0}$ : incident beam intensity or photon numbers, $\mathrm{t}$ : thickness of absorber, $\mu$ : linear attenuation coefficient, $\mathrm{I}(\mathrm{x})$ : the intensity transmitting through $\mathrm{t}$ thickness [2].

Linear attenuation coefficient varies with the density of the absorber, even though the absorber material is the same. For this reason, use of the linear attenuation coefficient is limited by the fact that it varies with density of the absorber. Therefore, the mass attenuation coefficient is much more widely used and is defined as;

$$
\mu_{\rho}=\frac{\mu}{\rho}
$$

where $\rho$ is the density of the absorber [1].

The interaction of radiation with matter can be simulated by Monte Carlo (MC) method. Some input data such as details of geometry of radiation source, target and medium, type of radiation, energy and direction of radiation flight, etc. are demonstrated in MC method. A simple diagram of a MC code is shown in Fig. 1 [3].

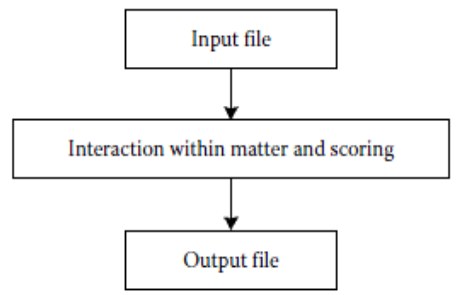

Figure 1. A simple diagram of a MC Code [3].

FLUKA is one of the well-known MC codes which is based on FORTRAN language. These are particle transport and interactions with matter, covering and extended range of applications spanning from proton and electron accelerator shielding to target design, dosimetry, detector design, etc. $[4,5]$.

ROOT is an object-oriented framework aimed at solving the data analysis challenges of high-energy physics. It works by depending on $\mathrm{C}++$. It is additionally used for advanced data analysis such as $\mathrm{MC}$ simulations in the field of subjects [6].

Sidhu et al. investigated the effect of collimator size and the absorber thickness on gamma-ray attenuation measurement by using a $\mathrm{NaI}(\mathrm{Tl})$ detector [7]. The gamma-ray attenuation coefficient of various absorber materials were experimentally determined by AbdelRahman et al. [8]. Singh et al. obtained gamma-ray mass attenuation coefficients of bismuth borate glasses by experimental and XCOM methods [9]. The gamma attenuation coefficients of the materials were investigated through an experimental method by Ermis and Celiktas [10].

\footnotetext{
${ }^{\mathrm{a}}$ Corresponding author: elermis@hotmail.com
} 
The gamma-ray mass attenuation coefficients of $\mathrm{NaI}$, PVT, GSO, GaAs and $\mathrm{CdWO}_{4}$ were theoretically determined at 60, 150, 500, 600, 1000 and $1250 \mathrm{keV}$ energies by means of FLUKA. Obtained attenuation coefficients were compared to the NIST values. It can be concluded that the results were highly compatible with each other.

\section{Simulation Configuration}

In the calculation procedure, FLUKA (ver. 2011.2c) program which was installed on an Ubuntu (ver. 13.10) operating system was used to obtain the gamma-ray attenuation coefficients of sodium iodide (NaI), polvinyltoluene (PVT), gadolinium silicate (GSO, $\mathrm{Gd}_{2} \mathrm{SiO}_{5}$ ), gallium arsenide (GaAs), and cadmium tungstate $\left(\mathrm{CdWO}_{4}\right)$ detector materials in this work. 60 , 150, 500, 600, 1000 and $1250 \mathrm{keV}$ energy gamma photons were sent to each detector material, respectively.

In the calculations, the materials were first formed in $1 \mathrm{~cm}$ thicknesses. Mono-energetic gamma rays of 60,150 , $500,600,1000$ and $1250 \mathrm{keV}$ were secondly sent to each detector material surface. The transmitted photon numbers from the materials were then detected. Built-in PRECISIO physics list was utilized for FLUKA program. The program was run ten cycles for each material, and the mass attenuation coefficient values were calculated by means of ROOT (ver. 5.34.18) which was used to analyze the output files of the program.

The attenuation coefficients of the materials via FLUKA were finally compared to the NIST ones.

\section{Results}

Calculated and the NIST mass attenuation coefficients of the used materials for $60,150,500,600,1,000$ and 1,250 keV-energy gamma photons are listed in Table 1.

In Fig. 2, the calculated mass attenuation coefficients versus the photon energies of each detector material are shown.

The graphs of calculated mass attenuation coefficients versus each gamma-ray energy and absorber densities are given in Fig. 3, respectively.

Table 1. Calculated mass attenuation coefficients according to different photon energies.

\begin{tabular}{|c|c|c|c|c|c|c|c|c|c|c|}
\hline 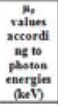 & PIT(g) & {$[2 \mathrm{E}(\mathrm{CW})$} & $\operatorname{Sal}(p-2) .6$ & $57 \mathrm{~g}(\mathrm{CW})$ & $\operatorname{Gans}(p=5$ & 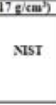 & $\operatorname{cso} 0.6-6.6$ & $10 \mathrm{~g}\left(\mathrm{~cm}^{\prime}\right)$ & Callo, & $900 \mathrm{~g}(\mathrm{Cl})$ \\
\hline 80 & $\begin{array}{l}0.189249 \\
=0.002007\end{array}$ & 0.18810 & & 6.45600 & & 2.04200 & & 8.50400 & & 3.79400 \\
\hline 150 & $\begin{array}{l}0.1461777 \\
+0.001876\end{array}$ & 0.14580 & $\begin{array}{l}.0 .609875 \\
=0.9003038\end{array}$ & 0.61120 & 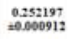 & 0.25000 & $\begin{array}{l}0.573503 \\
=0.007170\end{array}$ & 0.85410 & $\begin{array}{l}10.097897 \\
=0.025176\end{array}$ & 1.00600 \\
\hline 500 & $\begin{array}{l}0.006579 \\
0.0006571\end{array}$ & 0.99443 & $\begin{array}{l}.009981 \\
0.09060612\end{array}$ & 0.09497 & $\begin{array}{l}0.081736 \\
20.000519\end{array}$ & 0.082248 & $\begin{array}{l}0.105095 \\
20.000306\end{array}$ & 0.10710 & 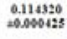 & 0.11470 \\
\hline 600 & $\begin{array}{l}\text { C.os6142 } \\
40.000632\end{array}$ & 0.0573 & $\begin{array}{l}\text { 20.083646 } \\
\text { :0.09000001 }\end{array}$ & 0.052125 & $\begin{array}{l}0.074573 \\
20.000005\end{array}$ & 0.07454 & $\begin{array}{l}0.090917 \\
20.000397\end{array}$ & 0.09039 & $\begin{array}{l}0.004738 \\
.00000014\end{array}$ & 0.09525 \\
\hline 1,900 & 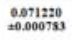 & 0.06594 & $\begin{array}{l}20.058918 \\
=0.0000334\end{array}$ & $0.085 s 1$ & $\begin{array}{l}\begin{array}{l}0.057114 \\
=0.0000395\end{array} \\
=0\end{array}$ & 0.09781 & $\begin{array}{l}0.061912 \\
=0.000315\end{array}$ & 0.06154 & 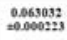 & 0.063: \\
\hline 1.250 & $\begin{array}{l}9.0599949 \\
* 0.000359\end{array}$ & 0.06166 & 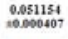 & 0.05162 & 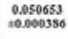 & 0.05122 & $\begin{array}{l}0.0533263 \\
-10.000267\end{array}$ & 0.05372 & $\begin{array}{l}\text { 20.053918 } \\
-0.0000239\end{array}$ & 0.05458 \\
\hline
\end{tabular}
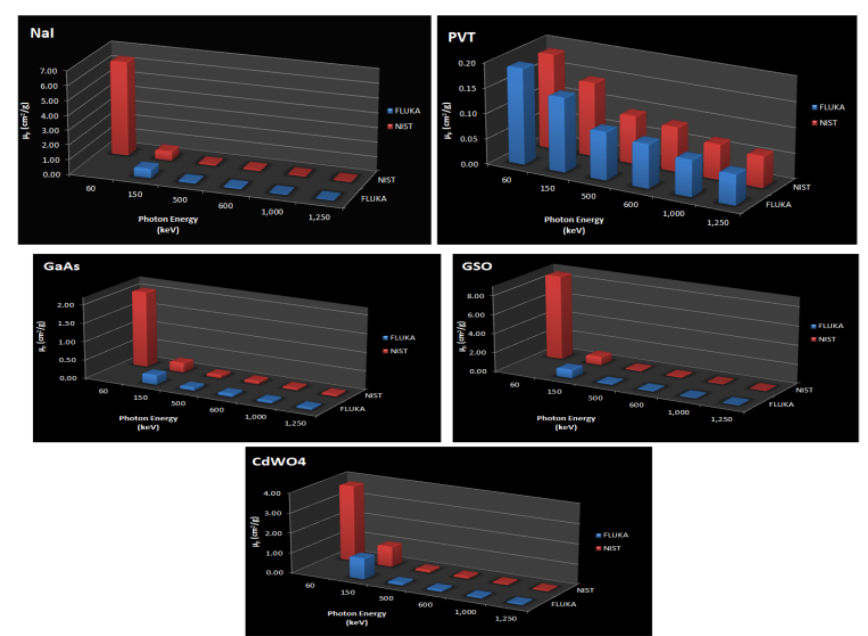

Figure 2. Gamma-ray mass attenuation coefficients vs. photon energies for NaI, PVT, GaAs, GSO and $\mathrm{CdWO}_{4}$.
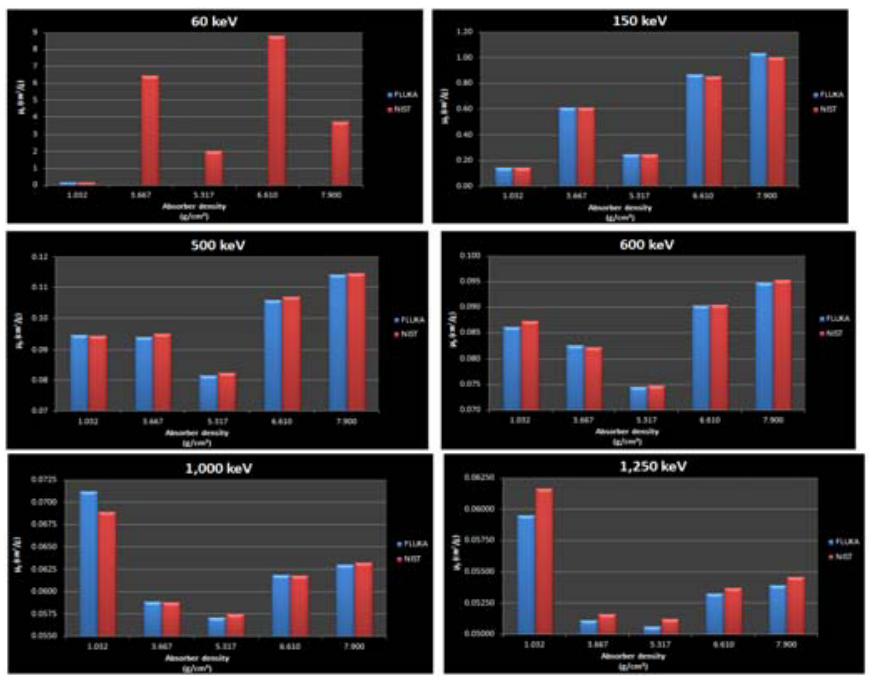

Figure 3. Gamma-ray mass attenuation coefficients vs. photon energies of $60,150,500,600,1,000$ and $1,250 \mathrm{keV}$ and absorber densities.

\section{Conclusion and Discussion}

In this work, gamma-ray mass attenuation coefficients of PVT, NaI, GaAs, GSO, and $\mathrm{CdWO}_{4}$ detector materials were theoretically calculated by means of FLUKA MC program at six different gamma-ray (photon) energies.

Calculated mass attenuation coefficients of the absorber materials through the theoretical method were listed in Table 1. The NIST values for these detector materials were also indicated in the same table.

NIST values and the gamma-ray mass attenuation coefficients calculated by FLUKA were highly compatible with each other for each detector material (Table 1). But the mass attenuation coefficients could not be calculated in lower energy region $(60 \mathrm{keV})$ and higher material density (Table 1) because no gamma-ray photons could transmit through the materials.

The mass attenuation coefficients of the used detector materials were also calculated by means of XCOM program (ver. 3.1) [11]. This program uses the NIST database. For this reason, obtained mass attenuation coefficients from this program were the same with those 
of the NIST values. Therefore, XCOM results were not given in the table.

Consequently, the compatibility of the attenuation coefficient results from FLUKA program with the NIST values leads us that FLUKA can be used as an alternative way to determine gamma-ray mass attenuation coefficients of the detector materials.

\section{Acknowledgement}

The Authors thank to Dr. Pilicer for his help in the calculation procedure.

\section{References}

1. G.F. Knoll, Radiation Detection and Measurement, John Wiley \& Sons. Inc, New York, (2000).

2. R.W. Leo, Techniques for Nuclear and Particle Physics Experiments, Springer-Verlag Berlin Heidelberg, Germany, (1987).

3. J.J.P. De Lima, Nuclear Medicine Physics, Taylor \& Francis, USA, (2011).

4. A. Ferrari, P.R. Sala, A. Fasso, J. Ranft, INFN/TC05/11, SLAC-R-773, (2005).

5. G. Battistoni, F. Cerutti, A. Fasso, A. Ferrari, S. Muraro, J. Ranft, S. Roesler, P.R. Sala, AIP Conference Proceeding 896, 31 (2007).

6. ROOT: An Object-Oriented Data Analysis Framework Users Guide 5.26, (2009).

7. G.S. Sidhu, K. Singh, P.S. Singh, G.S. Mudahar, Radiat. Phys. Chem. 56, 535 (1999).

8. M.A. Abdel-Rahman, E.A. Badawi, Y.L. AbdelHady, N. Kamel, Nucl. Instrum. Meth. A 447, 432 (2000).

9. K. Singh, H. Singh, V. Sharma, R. Nathuram, A. Khanna, J. Kumar, S.S. Bhatti, H.A. Sahota, . Instrum. Meth. B 194, 1 (2002).

10. E.E. Ermis, C. Celiktas, Int. J. Instrum. Sci. 1, 41 (2012).

11. M.J. Berger, J.H. Hubbell, 'NBSIR 87-3597', (1987). 